\title{
Enhanced oxygen transfer rate and bioprocess yield by using magnetite nanoparticles in fermentation media of erythromycin
}

\author{
Ghazal Labbeiki ${ }^{1}$, Hossein Attar ${ }^{1 *}$, Amir Heydarinasab ${ }^{1}$, Sayed Sorkhabadi ${ }^{2,3}$ and Alimorad Rashidi ${ }^{4}$
}

\begin{abstract}
Background: Magnetite nanoparticles have widespread biomedical applications. In the aerobic bioprocesses, oxygen is a limiting factor for the microbial metabolic rate; hence a high availability of oxygen in the medium is crucial for high fermentation productivity. This study aimed to examine the effect of using magnetite nanoparticles on oxygen transfer rate in erythromycin fermentation culture.
\end{abstract}

Methods: Magnetite nanoparticles were synthetized through co-precipitation method. After observing the enhanced oxygen transfer rate in deionized water enriched with magnetite nanoparticles, these nanoparticles were used in the media of by Saccharopolyspora erythraea growth to explore their impact on erythromycin fermentation titer. Treatments comprised different concentrations of magnetite nanoparticles, $(0,0.005,0.02 \mathrm{v} / \mathrm{v})$.

Results: In the medium containing $0.02 \mathrm{v} / \mathrm{v}$ magnetite nanoparticles, KLa was determined to be 1.89 time higher than that in magnetite nanoparticle-free broth. An improved 2.25 time higher erythromycin titer was obtained in presence of $0.02 \mathrm{v} / \mathrm{V}$ nanoparticles.

Conclusions: Our results, demonstrate the potential of magnetite nanoparticles for enhancing the productivity of aerobic pharmaceutical bioprocesses.

Keywords: Bioprocess, Oxygen transfer rate, Mass transfer coefficient (KLa), Magnetite nanoparticles, Pharmaceutical biotechnology, Fermentation, Erythromycin, Saccharopolyspora erythraea

\section{Background}

Oxygen is one of the most important substrate influencing productivity of aerobic bioprocesses [1]. While oxygen has a low solubility in most fermentation media, the uptake of the major amount of oxygen by microorganisms during the fermentation decreases the dissolved oxygen level in liquid to less than the critical concentration, rendering oxygen the limiting factor for productivity. A significantly low rate of oxygen transfer from gas into liquid, will lead to a decreased microbial metabolic rate, thereby low fermentation performance. Therefore an adequate supply of $\mathrm{O}_{2}$ is required for achieving a high fermentation productivity, particularly in high-cell

\footnotetext{
* Correspondence: Attar.h@srbiau.ac.ir

${ }^{1}$ Department of Chemical Engineering, Science and Research Branch, Islamic Azad University(IAU), Tehran, Iran

Full list of author information is available at the end of the article
}

density bioprocesses [2] such as erythromycin fermentation by Saccharopolyspora erythraea.

The Oxygen Transfer Rate (OTR) is usually determined by volumetric mass transfer coefficient (KLa). This variable is affected by several factors, including composition of medium, and geometrical and operating characteristic of the bioreactor [3]. Several methods have been proposed for improving KLa, including use of more effective agitation and aeration systems, enriching air with pure oxygen, reducing gas bubbles' size and enhancing gas hold up [2], and modifying physical properties of the medium by adding dispersed phases containing particles in size of $\mu \mathrm{m}$ [4] capable of solubilizing $\mathrm{O}_{2}$ more than water.

Recent studies have shown that nanomaterials have potential to positively influence the variables affecting biochemical processes. For instance, Olle et al. [4] showed that $\mathrm{O}_{2}$ mass transfer improves in the presence of colloidal nanoparticle dispersion. In addition, Nagi et al. [5] 
reported an enhanced oxygen mass transfer rate in the presence of nano-size particles.

Following this growing line of research, in the present study, first aqueous solution of magnetite nanoparticles (MNPs) was prepared. The solution was then added to the fermentation media of $S$. erythraea to examine the possible effects of magnetite nanoparticles on $\mathrm{O}_{2}$ transfer rate and final titer of fermentation product.

\section{Methods}

\section{Materials}

The erythromycin-producing strain Saccharopolyspora erythraea PTCC 1685 was obtained from Persian Type Culture Collection I-124, Iran. Soybean flour was supplied from Maxsoy Co., Iran. Chemical reagents and media were purchased from Merck or Sigma.

\section{Synthesis of nanoparticles}

Several procedures have been developed for synthesis of iron oxide nanoparticles [6,7]. In this study, coprecipitation technique was used for synthesis of magnetite nanofluid, which is based on the simultaneous precipitation of $\mathrm{Fe}_{3+}, \mathrm{Fe}_{2+}$ ions in basic aqueous media [6]. Some advantages of this method include being straightforward, cheap, and environment-friendly, and producing a uniform size distribution of nanoparticles.

To prepare solution of MNPs, $23.5 \mathrm{~g} \mathrm{FeCl}_{3} \cdot 6 \mathrm{H}_{2} \mathrm{O}$ and $8.6 \mathrm{~g} \mathrm{FeCl}_{2} \cdot 4 \mathrm{H}_{2} \mathrm{O}$ were dissolved in $25 \mathrm{ml}$ deionized water in an Erlenmeyer flask under Nitrogen sparging, $80^{\circ} \mathrm{C}$ and vigorous mechanical stirring. After $30 \mathrm{~min}$, $45 \mathrm{ml}$ of an aqueous solution of $\mathrm{NH}_{4} \mathrm{OH}$ was added to the mixture dropwise, after which the color of solution changes from light-brown to black, an indication of MNPs formation. The reaction was continued at $80^{\circ} \mathrm{C}$ under stirring and Nitrogen sparging conditions for 30 min to allow the substance completely crystalize. Afterwards the solution was cooled at room temperature $[4,8-10]$. The process reaction follows the following formula:

$$
\begin{aligned}
& \mathrm{FeCl}_{2}+2 \mathrm{FeCl}_{3}+8 \mathrm{NH}_{3}+4 \mathrm{H}_{2} \mathrm{O} \stackrel{1200 \mathrm{rpm}}{\longrightarrow} \mathrm{Fe}_{3} \mathrm{O}_{4} \\
& \quad+8 \mathrm{NH}_{4} \mathrm{Cl}
\end{aligned}
$$

Due to their strong magnetic properties, the synthetic MNPs were aggregated near the magnet. MNPs were then washed with deionized water three time sat the end of process. Next, NPs were dried in oven at $80^{\circ} \mathrm{C}$ overnight to be characterized by XRD and TEM analysis [4].

\section{Experimental determination of the volumetric mass transfer coefficient (KLa) by dynamic method}

According to the Dynamic method [11] for determining mass transfer coefficient, first the concentration of the dissolved oxygen in the liquid phase in reduced by means of Nitrogen bubbling until the oxygen concentration falls to zero. Afterwards, by bubbling the air into the reaction container the concentration of dissolved oxygen is increased [11-13]. The KLa can then be calculated using the two-film theory. According to this theory, the rate of oxygen transfer from gas phase into liquid phase (at cell-free systems) is represented by:

$$
\frac{d c}{d t}=K_{L} a\left(C^{*}-C_{L}\right)
$$

where $\mathrm{dc} / \mathrm{dt}$ is the accumulation rate of the oxygen in the liquid phase, KLa represents the lumped volumetric mass transfer coefficient, $C^{*}$ denotes the saturate concentration of the dissolved oxygen in the broth, and $\mathrm{C}_{\mathrm{L}}$ represents the dissolved oxygen concentration in the aqueous phase [14]. Integrating Equation 1 will result in Equation 2:

$$
\int_{C_{L 1}}^{C_{L 2}} \frac{d C_{L}}{C^{*}-C_{L}}=\int_{t 1}^{t 2} K_{L} a \cdot d t
$$

With CL1 $=0$ at $\mathrm{t} 1=0$, the integrated form of Equation (2) can be represented as the Equation 3:

$$
\ln \frac{C^{*}-C_{L 2}}{C^{*}}=-K_{L} a \cdot t_{2}
$$

A plot of $\ln \frac{C^{*}-C_{L}}{C^{*}} v s$. $\mathrm{t}$ will result in a straight line with slope of -KLa $[12,14]$.

\section{Media and cultural method}

Spores of S. erythraea were produced on slants of CSL agar medium after 14 days in incubator at $30^{\circ} \mathrm{C}$ [15]. Ingredients of the sporulation medium used in this study was (per liter): $10 \mathrm{~g}$ CSL, $10 \mathrm{~g}$ starch, $2.5 \mathrm{~g} \mathrm{CaCO}_{3}, 3 \mathrm{~g}$ $\left(\mathrm{NH}_{4}\right) 2 \mathrm{SO}_{4}, 3 \mathrm{~g} \mathrm{NaCl}, 20 \mathrm{~g}$ agar, $2 \mathrm{ml}$ trace element $\left(\mathrm{MgSO}_{4} .7 \mathrm{H}_{2} \mathrm{O}, \quad \mathrm{FeSO}_{4} .7 \mathrm{H}_{2} \mathrm{O}, \quad \mathrm{ZnSO}_{4} .7 \mathrm{H}_{2} \mathrm{O}, \mathrm{CuSO}_{4} .5\right.$ $\mathrm{H}_{2} \mathrm{O}, \mathrm{CoCl}_{2} \cdot 6 \mathrm{H}_{2} \mathrm{O}, \mathrm{HCL} 37 \%$ ), $\mathrm{pH} 7 \pm 0.1$ [15]. A volume of $1 \mathrm{ml}$ of spore suspension of strain was inoculated in a $1000 \mathrm{ml}$ Erlenmeyer flask containing $100 \mathrm{ml}$ of seeding medium and incubated at $30^{\circ} \mathrm{C}$ and $220 \mathrm{rpm}$ for 48 hours on a shaker-incubator. The composition of seeding medium used in this study was (per liter): $30 \mathrm{~g}$ soybean meal, 10 g glucose, 10 g glycerol, $3.5 \mathrm{~g}\left(\mathrm{NH}_{4}\right) 2 \mathrm{SO}_{4}$, $1 \mathrm{~g}\left(\mathrm{NH}_{4}\right) 2 \mathrm{HPO}_{4}, 5 \mathrm{~g} \mathrm{CaCO}_{3}, \mathrm{pH} 7 \pm 0$ [15]. Based on strain's morphology (Figure 1), culture's $\mathrm{pH}$ and biomass, the best inoculum was selected to be inoculated $(5 \% \mathrm{v} / \mathrm{v})$ into fermentation flasks. Fermentations were carried out in 9 Erlenmeyer flasks of $1000 \mathrm{ml}$, containing $150 \mathrm{ml}$ of fermentation media. The composition of fermentation media was (per liter): $30 \mathrm{~g}$ soybean meal, $40 \mathrm{~g}$ dextrin, $30 \mathrm{~g}$ starch, $2 \mathrm{~g}\left(\mathrm{NH}_{4}\right) 2 \mathrm{SO}_{4}, 0.15 \mathrm{~g}\left(\mathrm{NH}_{4}\right) 2 \mathrm{HPO}_{4}, 10 \mathrm{~g}$ $\mathrm{CaCO}_{3}, 50 \mathrm{~g}$ rapeseed oil, $\mathrm{pH}$ 6.8. Two concentrations of MNPs $(0.005,0.02 \mathrm{v} / \mathrm{v})$ were added to each fermentation flask. Flasks were then put in shaker-incubator at $33^{\circ} \mathrm{C}$ 


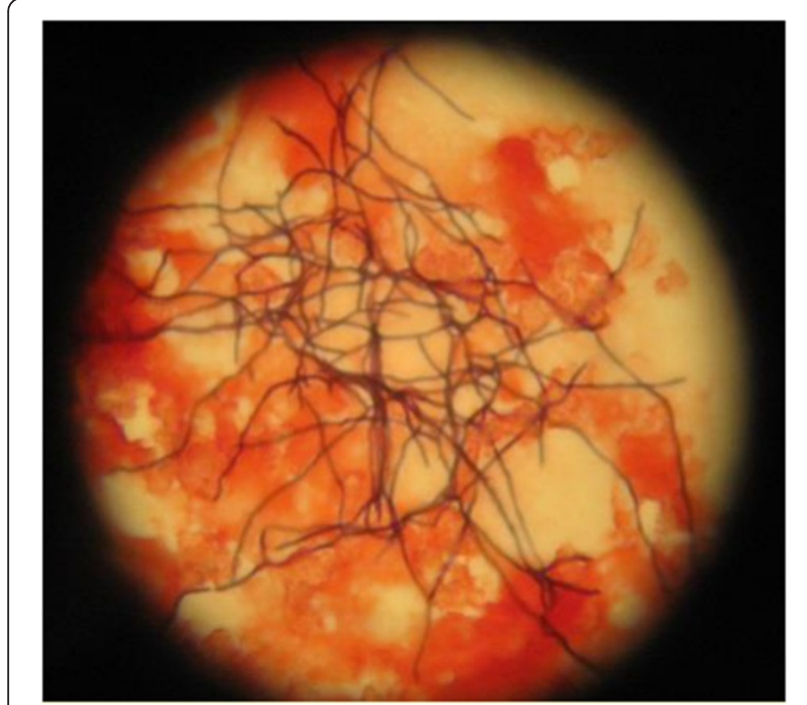

Figure 1 The mycelia of strain used as inoculum.

and $220 \mathrm{rpm}$ for 11 days [15-17]. All experiments were performed in triplicate in six batches. Samples of $7 \mathrm{ml}$ were taken on days 6, 8, and 10 for further analysis. Investigation of $S$. erythraea morphology indicated that the hyphae of the strain were lysed on day 12 , hence, no further erythromycin production was occurred.

\section{Erythromycin assay}

Purification of erythromycin was carried out by centrifugation of the samples (4000 rpm, $20 \mathrm{~min}$ ) followed by using magnet to separate the possibly remaining magnetite nanoparticles from the supernatant. The supernatant was then diluted with $0.2 \mathrm{M}$ carbonate-bicarbonate buffer of pH9.6 and the total erythromycin was extracted with chloroform. The extracted erythromycin was then mixed with the bromophenol blue reagent. The absorbance of

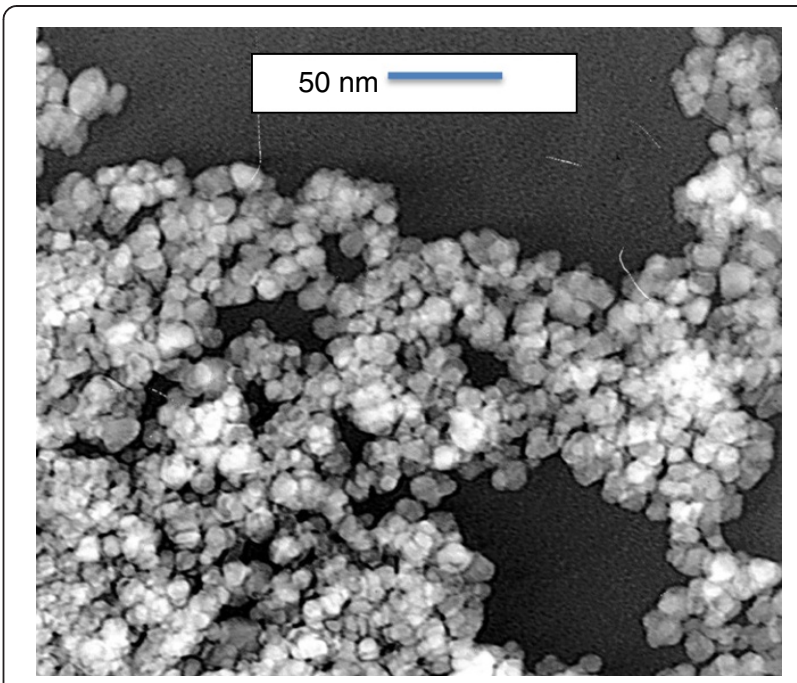

Figure 3 TEM image of magnetite nanoparticles.

organic phase was measured at $415 \mathrm{~nm}$ by spectrophotometry [15-17].

\section{Statistical analysis}

T-test was used to examine the significance of the mean differences. KLa was calculated from regression analysis. $\mathrm{P}<0.05$ was considered as the statistical significance.

\section{Results and discussion}

\section{Nanoparticles characterization}

\section{NPs' crystal structure}

The crystal structure of the synthetized MNPs is characterized by X-ray powder diffraction (XRD) [9]. Figure 2 displays the structural properties of the MNPs as determined by XRD (Bruker axs D4, cu, step size 0.02). The XRD pattern shows the diffraction peaks at $2 \theta=18.270^{\circ}$, $30.035^{\circ}, 35.423^{\circ}$ (strongest line), $43.053^{\circ}, 53.392^{\circ}, 56.944^{\circ}$,

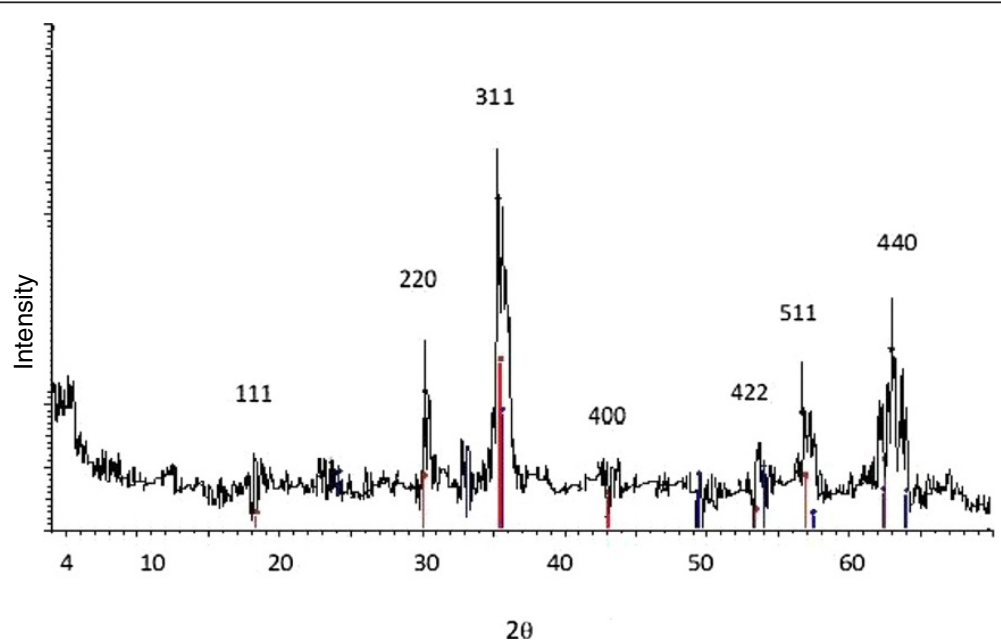

Figure 2 XRD pattern of synthetic nanoparticles. 


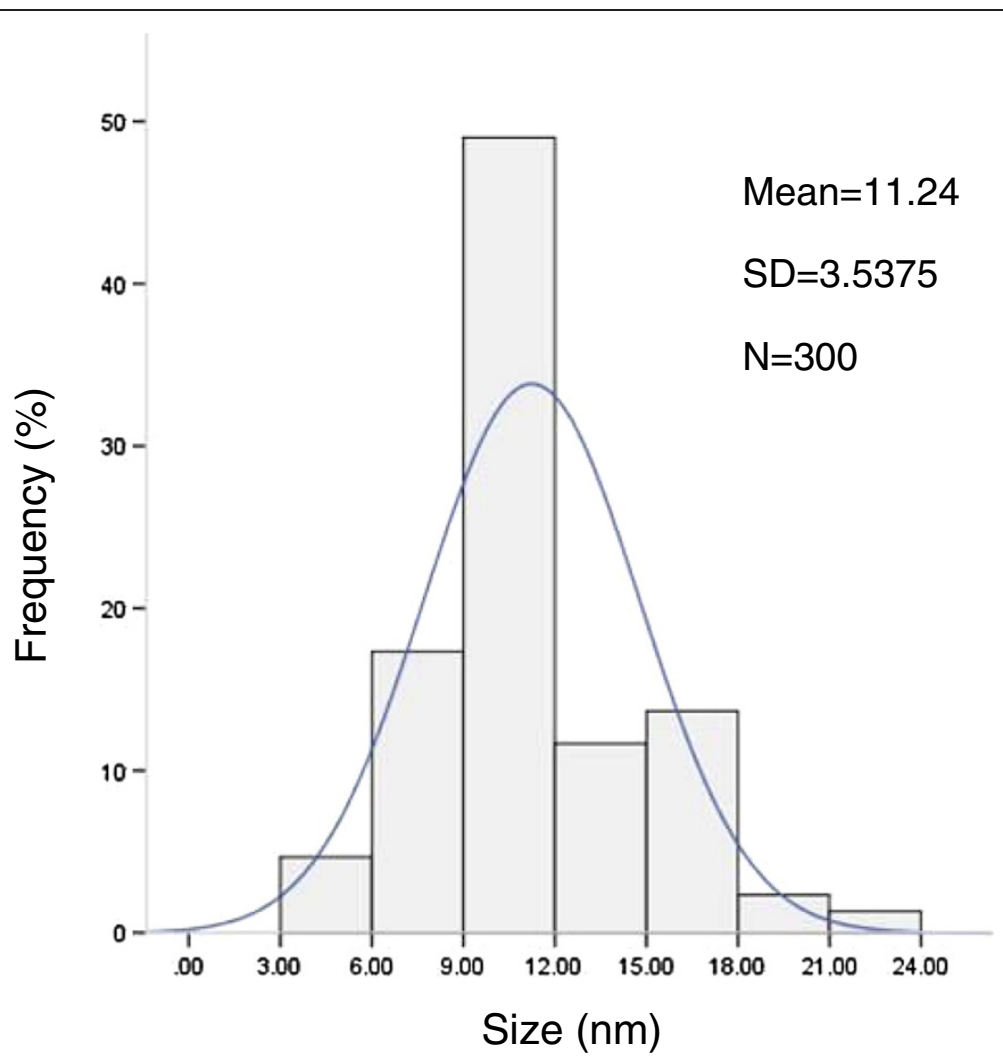

Figure 4 The size distribution of magnetite nanoparticles.

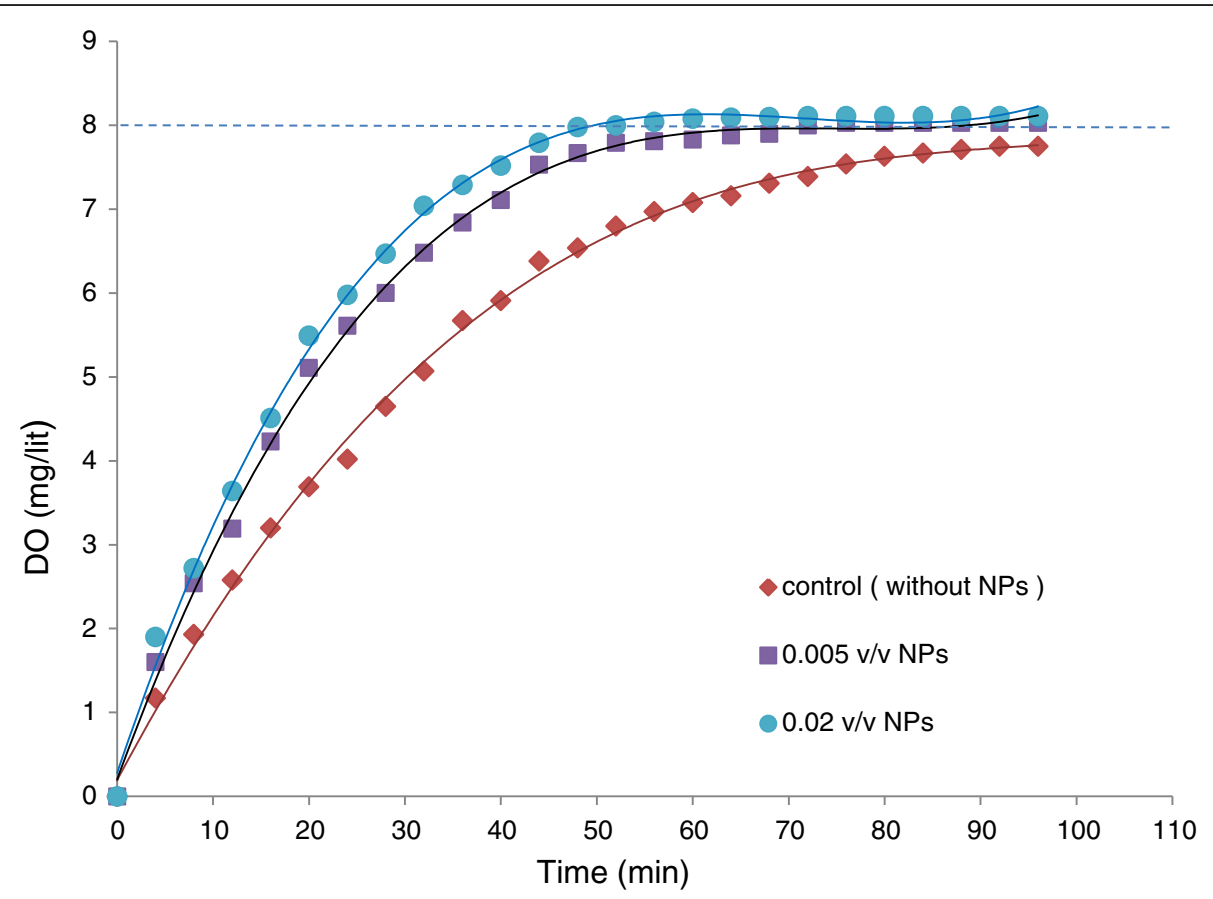

Figure 5 The dissolved oxygen at different concentrations of MNPs (each value in the figure is the mean of corresponding values from 3 repeated experiments). 


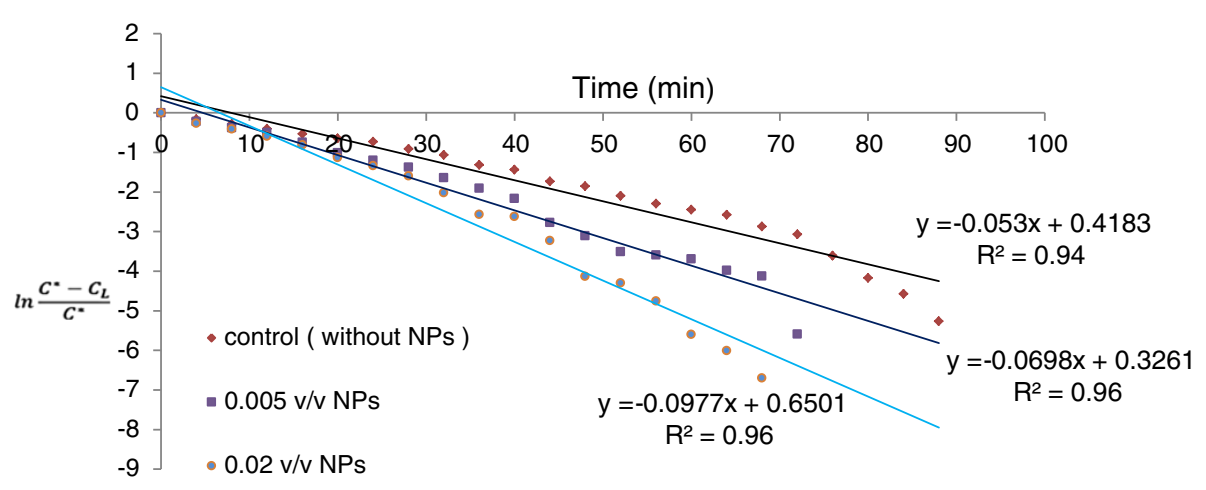

Figure 6 The linearized curve of dissolved oxygen at different concentrations of MNPs (the slope of the curve represents-KLa).

$62.516^{\circ}$, which correspond to the (111), (220), (311), (400), (422), (511), (440) reflections, respectively [9,18-20].The XRD results show that the synthetized MNPs are well crystallized and the relative intensity of the diffraction peaks matches well with the reported XRD data for magnetite nanoparticles in the literature.

\section{NPs' size}

Morphology and size of the prepared MNPs was determined by Transmission Electron Microscopy (TEM) (Figure 3) [10,21-23]. A small amount of dried MNPs were dissolved in ethanol. The solution was then sonicated for better dispersion. A drop of the solution was then placed on a 200 mesh Copper grid and dried in the air. The sample was analyzed by TEM at $100 \mathrm{KV}$.
Diameter of the MNPs was determined directly from the TEM image [24]. Figure 4 displays the histogram of NPs' size distribution $(\mathrm{n}=300)$. A mean $(\mathrm{SD})$ size of particles is $11.24(3.5) \mathrm{nm}$ was calculated.

\section{Effect of nanoparticles on mass transfer coefficient}

The changes in concentration of dissolved oxygen in deionized water at different concentrations of MNPs were measured during the absorption process, based on Dynamic method $[11,12]$, and compared with nanoparticlefree water, as the control. As shown in Figure 5, at all concentrations of MNPs, the amount of DO has increased and the time for achieving saturate concentration has decreased, when compared with the control. KLa was determined using the linearized curve of DO vs. time (see Methods). As shown in Figure 6, MNPs positively

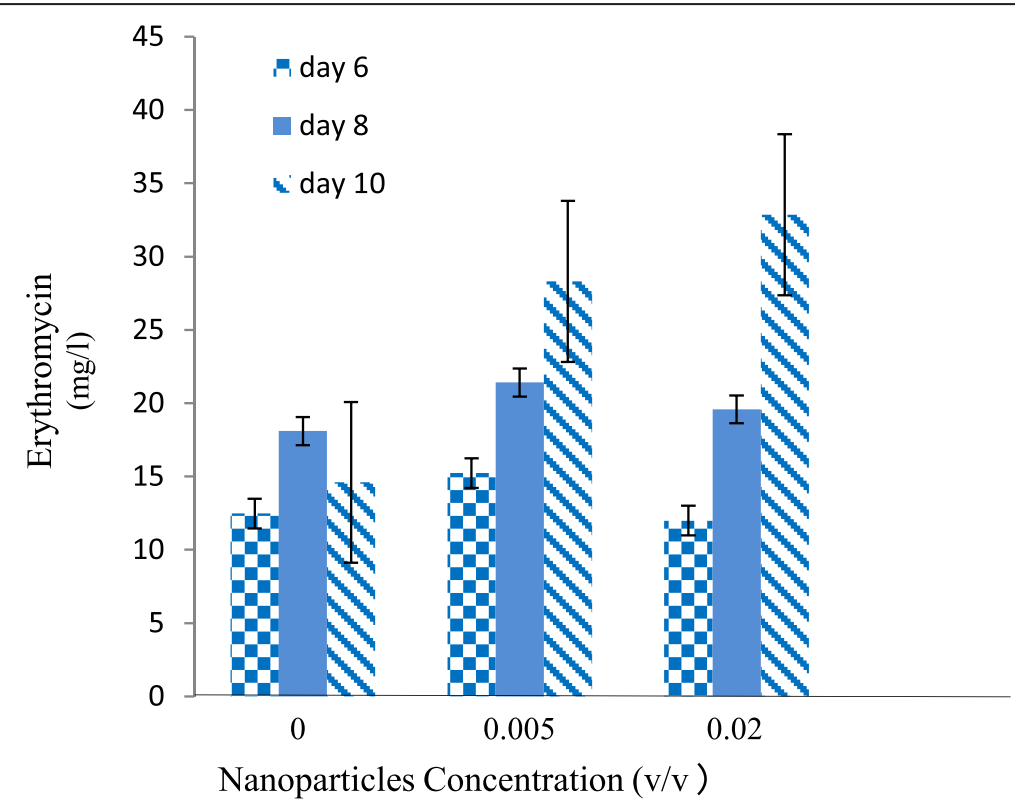

Figure 7 Effect of different concentrations of nanoparticles on the production of erythromycin by S. erythraea (each value on the figure is the mean of corresponding values from 12 repeated experiments). 
affects the mass transfer coefficient; KLa in water containing $0.02 \mathrm{v} / \mathrm{v}$ MNPs is 1.85 times higher than that in the control.

\section{Effect of MNPs on erythromycin titer}

Magnetite MNPs with initial concentrations of zero (control medium), 0.005, $0.02 \mathrm{v} / \mathrm{v}$ were used in fermentation media of S. erythraea and their effect on erythromycin titer was examined. As shown in Figure 7, while the maximum concentration of erythromycin is 18.1 $\mathrm{mg} /$ lit in the control medium, in the medium with 0.02 v/v MNPs, a maximum titer of $32.86 \mathrm{mg} / \mathrm{lit}$ has obtained which is 2.25 times higher. Erythromycin final titer (day 10) in both 0.005 and $0.02(\mathrm{v} / \mathrm{v})$ media shows significant difference as compared with the control $(\mathrm{P}<0.05)$. Figure 6 shows that this higher titer is due to the more prolonged production of erythromycin in MNP-containing medium compared to the control medium. It could be aurged that this higher titer is due to an extended viability of the microorganism as a result of higher OTR in the presence of MNPs.

The chief objective of the present study was to explore the impact of MNPs on OTR and thereby titer of bioprocess product. MNPs are strong oxygen absorbent due to their increased surface area at nano scale. These nanoparticles have proven useful when used as recyclable oxygen carriers in aerobic fermentation [25]. A number of mechanisms proposed for the positive impact of MNPs on OTR include enhancing oxygen solubility in the fermentation medium, inducing microconvection in the surrounding fluid by Brownian motion [4], and enlarging the gas-liquid interfacial surface through being adsorbed on the air bubbles, preventing them from coalescence [26].

Results obtained in this study, which are in close agreement with the findings from previous researches [4,25-27], add weight to the notion of MNPs being candidate members of $\mathrm{O}_{2}$-vectors that promote the oxygen transfer in stirred aerobic bioprocesses.

Composition of fermentation medium plays an important role in the titer of secondary metabolites and the cost of fermentation product [15]. Because the erythromycin producing bacterium, $S$. erythraea is an aerobic actinomycete, proper oxygenation is crucial to achieve a high yield of this substance. Our results clearly indicate that presence of MNPs remarkably enhance the erythromycin production by $S$. erythraea.

Possible toxicity of nanoparticles is a major concern, particularly when used in pharmaceutical bioprocesses $[28,29]$. The fact that MNPs can be efficiently separated from fermentation medium, virtually eliminate the risk of possible toxic effects. On the other hand, the wide use of MNPs in environmental applications, including pollutant removal, toxicity mitigation, and water and waste treatment [30] indicates the safety of its use at limited doses. These advantages together with their positive impact on fermentation productivity as supported in this study, introduce use of them as a viable strategy for an improved pharmaceutical bioprocessing.

\section{Conclusions}

The metabolic rate and growth of microbial biocatalysts are controlled by oxygen; hence, for an improved yield of aerobic bioprocesses, there is a need for strategies enabling a high rate oxygen transfer, while maintain affordable energy consumption. Our results indicate that MNPs can improve the efficiency of oxygen transfer in the fermentation medium. Use of MNPs in the erythromycin fermentation culture enhanced erythromycin titer, presumably via promotion of microbial growth and viability. The straightforward and inexpensive synthetize of these biocompatible, non-toxic and non-volatile nanoparticles, together with their positive impact on oxygen transfer rate, introduce them as promising agents for achieving an enhanced productivity of the industrial bioprocesses.

\section{Competing interests}

The authors declare that they have no competing interests.

\section{Authors' contributions}

$\mathrm{HA}$ and $\mathrm{AH}$ jointly conceived and designed the study and contributed to the revision of the manuscript. GL made the major contribution to performing the experiments, summarizing and interpretation of the results, and drafting the manuscript. AR was involved in statistical analyses and drafting the manuscript. SMRS coordinated the study procedure and contributed to revision of the manuscript. All authors read and approved the final manuscript.

\section{Acknowledgements}

The authors wish to thank Dr. Meysam Mobasheri for participating in statistical analysis and revision of the manuscript.

\section{Author details}

1 Department of Chemical Engineering, Science and Research Branch, Islamic Azad University(IAU), Tehran, Iran. ${ }^{2}$ Department of Pharmacology, School of Advanced Sciences and Technologies in Medicine, Tehran University of Medical Sciences, Tehran, Iran. ${ }^{3}$ Department of Toxicology and Pharmacology, Islamic Azad University of Pharmaceutical Sciences Branch, Tehran, Iran. ${ }^{4}$ Catalyst and Nanotechnology Division, Research Institute of Petroleum Industry, Tehran, Iran.

Received: 10 August 2014 Accepted: 7 September 2014

Published online: 16 September 2014

\section{References}

1. Garcia-Ochoa F, Gomez E, Santos VE, Merchuk JC: Oxygen uptake rate in microbial processes. Biochem Eng J 2010, 49:289-307.

2. Fadavi $A$, Chisti $Y$ : Gas-Liquid mass transfer in a novel forced circulation loop reactor. Chem Eng J 2005, 112:73-80.

3. Moutafchieva D, Popova D, Dimitrova M, Tchaoushev S: Experimental determination of the volumetric mass transfer coefficient. J Chem Technol Metallurgy 2013, 48(4):351-356.

4. Olle B, Bucak S, Holmes TC, Bromberg L, Hatton TA, Wang DIC: Enhancement of oxygen mass transfer using functionalized magnetic nanoparticles. Ind Eng Chem Res 2006, 45:4355-4363.

5. Nagy E, Feczko T, Koroknai B: Enhancement of oxygen mass transfer rate in the presence of nanosized particles. Chem Eng Sci 2007, 62:7391-7398.

6. Figuerola A, Di Corato R, Manna L, Pellegrino T: From iron oxide NPs towards advanced iron-based inorganic materials designed for biomedical applications. J Pharmacol Res 2010, 62:126-143. 
7. Lu AH, Salabas EL, Schuth F: Magnetic NPs: synthesis, protection, functionalization, and application. Angew Chem Int Ed Engl 2007, 46:1222-1244

8. Sun J, Zhou SH, Hou P, Yang Y, Weng J, Li X, Li M: Synthesis and characterization of biocompatible Fe304 Nanoparticles. J Biomed Mater Res 2006, A:333-341.

9. Awwad AM, Salem NM: A green and facile approach for synthesis of magnetite NPs. Nanosci Nanotechnol 2012, 2(6):208-213.

10. Kafayati ME, Raheb J, TorabiAngazi M, Alizadeh SH, Bardania H: The Effect of magnetic Fe3O4 NPs on the growth of genetically manipulated bacterium, Pseudomonas aeruginosa. Iran J Biotechnol 2013, 11(1):41-46.

11. Garcia-Ochoa F, Gomez E: Bioreactor scale-up and oxygen transfer rate in microbial processes: an overview. Biotechnol Adv 2009, 27:153-176.

12. Juarez $P$, Orejas J: Oxygen transfer in a stirred reactor in laboratory scale. Lat Am Appl Res 2001, 31:433-439.

13. Haribabu K, Sivasubramanian V: Determination of mass transfer coefficient in an inverse fluidized bed reactor using statistical and dynamic method for a non-Newtonian fluid. J Sci Ind Res 2013, 72:485-490.

14. Nielsen DR, Daugulis AJ, McLellan PJ: A novel method of simulating oxygen mass transfer in two-phase partitioning bioreactors. J Biotech Bioeng 2003, 83(6):735-742.

15. Hamedi J, Malekzadeh F, Saghafi-nia AE: Enhancing of erythromycin production by Saccharopolysporaeryhtraea with common and uncommon oils. J Microb Biotechnol 2004, 31:447-456.

16. Rostamza M, Noohi A, Hamedi J: Enhancement in production of erythromycin by Saccharopolyspora erythraea by the Use of suitable industrial seeding-media. Daru J Pharm Sci 2008, 1:13-17.

17. Hamedi J, Khodagholi F, Hassani-Nasab A: Increased erythromycin production by alginate as a medium ingredient or immobilization support in cultures of Saccharopolyspora erythraea. Biotechnol Lett 2005, 27:661-664.

18. Wang B, Wei Q, Qu SH: Synthesis and characterization of uniform and crystalline magnetite nanoparticles via oxidation-precipitation and modified co-precipitation method. Int J Electrochem Sci 2013, 8:3786-3793.

19. Shaker S, Zafarian SH, Chakra SH, Rao KV: Preparation and characterization of magnetite nanoparticles by Sol-Gel method for water treatment. Int J Inn Res Sci Eng Technol 2013, 2(7):2969-2973.

20. Bahrampour F, Raheb J, Rabiei Z: Alteration in protein profile of Pseudomonas aeruginosa (PTSOX4) coated with magnetic nanoparticles. J Nanostructure Chem 2013, 3(58):1-8.

21. Wang R, Zuo SH, Zhu W, Zhang J, Fang J: Rapid synthesis of AqueousPhase magnetite nanoparticles by atmospheric pressure Non-Therma microplasma and their application in magnetic resonance imaging. Plasma Process Polym 2014, 11(5):448-454.

22. Giraldo L, Moreno-Pirajan JC: Synthesis of magnetite nanoparticles and exploring their application in the removal of $\mathrm{Pt} 2+$ andAu3 + ions from aqueous solutions. Eur Chem Bull 2013, 7:445-452.

23. Mahmed N, Eczko OH, Soderberg O, Hannula SP: Room temperature synthesis of magnetite nanoparticles by a simple reverse Co-Precipitation method. Mater Sci Eng 2011, 18:1-4.

24. Ghalamboran MR, Ramsden J, Ansari F: Growth rate enhancement of Bradyrhizobium japanicum due to magnetite nanoparticles. J Bionanosci 2009, 3:1-6.

25. Bromberg LE, Hatton TA, Wang IC, Yin J, Olle B: Bioprocesses enhanced by magnetic nanoparticles, United States patent. 2006, US0040388A1:1-23.

26. Dobre T, Ohreac BS, Parvulescu OC, Danciu TD: Effect of solid carriers on oxygen mass transfer in a stirred tank bioreactor. REVCHIM (Bucharest) 2014, 65(4):489-496.

27. Saeednia L, Hashemi Pour H, Afzali D: Effect of nanoparticles on gas-liquid mass transfer coefficient. Iran Chem Eng J 2013, 12(66):50-57.

28. Mostafalou S, Mohammadi H, Ramazani A, Abdollahi M: Different biokinetics of nanomedicines linking to their toxicity; an overview. Daru J Pharm Sci 2013, 21:14
29. Mogharabi M, Abdollahi M, Faramarzi M: Toxicity of nanomaterials; an undermined issue. Daru J Pharm Sci 2014, 22:59.

30. Tang SCN, Lo IMC: Magnetic nanoparticles: essential factors for sustainable environmental applications. J Water Res 2013, 47:2613-2632.

doi:10.1186/s40199-014-0066-5

Cite this article as: Labbeiki et al.: Enhanced oxygen transfer rate and bioprocess yield by using magnetite nanoparticles in fermentation media of erythromycin. DARU Journal of Pharmaceutical Sciences 2014 22:66

\section{Submit your next manuscript to BioMed Central and take full advantage of:}

- Convenient online submission

- Thorough peer review

- No space constraints or color figure charges

- Immediate publication on acceptance

- Inclusion in PubMed, CAS, Scopus and Google Scholar

- Research which is freely available for redistribution

Submit your manuscript at www.biomedcentral.com/submit
C BioMed Central 